\title{
Mediastinal Neurogenic Neoplasm
}

National Cancer Institute

\section{Source}

National Cancer Institute. Mediastinal Neurogenic Neoplasm. NCI Thesaurus. Code C6624.

A neurogenic tumor that arises from the mediastinum. Neural tumors are the most common tumors that arise from the posterior mediastinum. Representative examples include Schwannoma, neurofibroma, and neuroblastoma. 